\title{
Influence of Selenium on the Internal Oxidation of Fe-Si-Al-C Alloy
}

\author{
Darja STEINER PETROVIČ \\ Institute of Metals and Technology, Lepi pot 11, 1000 Ljubljana, Slovenia. \\ (Received on April 5, 2011; accepted on May 26, 2011)
}

\begin{abstract}
The effect of selenium on the oxidation of $\mathrm{Fe}-\mathrm{Si}-\mathrm{Al}-\mathrm{C}$ alloy during decarburization at $840^{\circ} \mathrm{C}$ in wet hydrogen was studied. Selenium was found to change the morphology of internal oxides of an Fe-Si-Al-C alloy. The long penetrating internal oxides of Si and $\mathrm{Al}$ in the alloy containing 0.034 at.\% Se demonstrate an obvious preferential growth perpendicular to the steel substrate. FEG-SEM/EDX was performed to analyze the scale and the subscale. It was assumed that columnar morphology of internal oxides could be induced by selenium surface segregation. Therefore, in-situ AES analysis using a resistive heating of specimen in UHV was used to obtain more accurate data on temperature dependence of selenium surface segregation in silicon steel. Additionally, the kinetics of the selenium surface segregation was investigated in-situ during annealing at $840^{\circ} \mathrm{C}$ in the ultra-high vacuum chamber of a field-emission Auger electron spectrometer.
\end{abstract}

KEY WORDS: steel; internal oxidation; selenium; surface segregation.

\section{Introduction}

Most of the electrical energy produced in the world is consumed in electrical motors. ${ }^{1)}$ They are incorporated in a wide range of equipment, from the simplest domestic appliances to (hybrid) electric vehicles. The non-oriented electrical steel sheet is used as a steel core of electric motors. Therefore, there is an enormous motivation for research on their optimization. ${ }^{1)}$

Desirable magnetic properties of non-oriented electrical steel sheets are strongly dependent on carbon content. A decarburization stage for these steels is one of the most important phases in their production. ${ }^{2)}$ The carbon content in electrical steel sheets should be less than $25 \mathrm{ppm}$ to avoid magnetic aging. ${ }^{3)}$

The decarburization is usually performed by annealing in a wet hydrogen atmosphere in a temperature range from $700-900^{\circ} \mathrm{C}$ with a controlled partial pressure ratio of water vapor and hydrogen $p\left(\mathrm{H}_{2} \mathrm{O}\right) / p\left(\mathrm{H}_{2}\right)$. To achieve effective decarburization, the dew point of decarburizing atmospheres is changed from +10 to $+60^{\circ} \mathrm{C}$. ${ }^{4}$

Decarburization process of steel in a $\mathrm{H}_{2} / \mathrm{H}_{2} \mathrm{O}$ gas mixture can be described as a sequence of the following steps:

1. Diffusion of carbon to the steel surface

2. Transport of water vapor to the steel surface and equilibration at the phase boundary steel-gas mixture

3. Dissociation of water vapor molecules into a hydrogen and oxygen adsorbing on the steel surface

4. Oxidation of carbon

5. Oxidation of iron and alloying elements

The basic chemical reactions of the decarburization of the steel in $\mathrm{H}_{2} / \mathrm{H}_{2} \mathrm{O}$ gas mixtures are:

$$
\begin{array}{r}
{[\mathrm{C}]_{\mathrm{Fe}}+\mathrm{H}_{2} \mathrm{O}=\mathrm{CO}+\mathrm{H}_{2} \ldots \ldots .} \\
{[\mathrm{C}]_{\mathrm{Fe}}+2 \mathrm{H}_{2} \mathrm{O}=\mathrm{CO}_{2}+2 \mathrm{H}_{2} \ldots} \\
{[\mathrm{C}]_{\mathrm{Fe}}+2 \mathrm{H}_{2}=\mathrm{CH}_{4} \ldots \ldots \ldots} \\
{[\mathrm{C}]_{\mathrm{Fe}}+\mathrm{CO}_{2}=2 \mathrm{CO} \ldots \ldots \ldots .}
\end{array}
$$

The principal reaction that controls the decarburization is Eq. (1); the reaction according to Eq. (3) can be neglected when the $p\left(\mathrm{H}_{2} \mathrm{O}\right) / p\left(\mathrm{H}_{2}\right)$ ratios are greater than 0.01.5)

Besides the carbon content which determines the magnetic ageing of electrical steel sheets the magnetic properties also critically depend on the microstructure, e.g., the grain size, the content of non-metallic inclusions, the oxide scale, the crystallographic texture, and nanostructure..$^{1,2,6-8)}$ It is reported that in electrical steel sheets the oxide layer increases core loss by $0.05-0.07 \mathrm{~W} / \mathrm{kg}$ per $1 \mu \mathrm{m}$ of subscale thickness. ${ }^{4)}$ In general, the oxidation behaviour of steels is greatly influenced by the surface conditions. Alloying elements and segregands may influence the oxidation speed, the mechanism and the morphology of the scale.

Selenium can be introduced into the melts in the steel processing route, normally as impurity in the manganese metal. ${ }^{9}$ About some positive effects of the selenium on the texture formation and the magnetic properties of the nonoriented electrical steels have already been reported. It is likely that the growth of the grains with soft magnetic orientations near the plane (001) is to be enhanced. ${ }^{10)}$ In contrast to this conclusions, Beyer and Grabke ${ }^{11)}$ reported that in interstitial-free steels selenium addition resulted in significantly enhanced $\gamma$-fibre and formation of $\{111\}<110>$ $\{111\}<112>$ textures. 
The studies already performed on the influence of selenium on the properties of non-oriented electrical steel sheets have revealed that selenium as a surface active element has a tendency to segregate on free surfaces and that the selenium forms (complex) selenide inclusions. ${ }^{10,12)}$ Since the aim of this study was to elucidate the influence of selenium on the oxidation behaviour of an Fe-Si-Al-C alloy, the selenium surface segregation in silicon steel was additionally studied.

In this paper, more accurate data on temperature dependence of selenium surface segregation in silicon steel are presented. Obtained results base on an improved methodology described elsewhere ${ }^{13)}$ for the experimental in-situ AES study of surface segregation in polycrystalline ferritic $\mathrm{Fe}-$ $\mathrm{Si}-\mathrm{Al}$ alloys using the technique of measuring of the cumulative values of the segregand(s) without intermediate ion sputtering.

In addition, the kinetics of the selenium surface segregation was investigated in-situ during annealing at the typical temperature of decarburization annealing, e.g. $840^{\circ} \mathrm{C}$.

\section{Experimental}

\subsection{Specimens}

In this investigation the specimens of two laboratory manufactured cold-rolled $\mathrm{Fe}-\mathrm{Si}-\mathrm{Al}-\mathrm{C}$ alloys were used; one of them was doped with 0.034 at.\% Se. Their chemical composition is given in Table 1.

\subsection{Heat Treatment}

Prior to experiments the specimens were metallographically prepared by grinding and polishing. Final polishing was carried out with colloidal silica $(0.25 \mu \mathrm{m})$. The specimens were oxidized in a mixture of hydrogen and water vapor at $840^{\circ} \mathrm{C}$. The time of annealing was 15 minutes, the dew point of the gas mixture was $50^{\circ} \mathrm{C}$, corresponding to $p\left(\mathrm{H}_{2} \mathrm{O}\right) / p\left(\mathrm{H}_{2}\right)=0.12$. To saturate hydrogen with water vapor water bath saturator was used. Specimens were submitted into the hot zone of the furnace when the working temperature was reached. After annealing the specimens were cooled in helium to room temperature.

\subsection{Characterization of Scale}

Post-exposure characterization of scales was performed using FEG(SEM/EDX).

Cross-sections of the steel sheets after oxidation/decarburization were metallographically prepared by grinding and polishing for FEG(SEM/EDX) analyses. FEG(SEM/ EDX) analyses were performed using a JEOL JSM 6500-F electron microscope. To enhance the electrical conductivity the polished cross-sections of the steel specimens were sputtered with approximately $5 \mathrm{~nm}$-thick carbon layer.

Table 1. Chemical composition of the investigated steel sheets.

\begin{tabular}{llcccccccc}
\hline Specimen & & $\mathbf{C}$ & $\mathbf{S i}$ & $\mathbf{A l}$ & $\mathbf{M n}$ & $\mathbf{C u}$ & $\mathbf{P}$ & $\mathbf{S}$ & Se \\
\hline L-Se19 & at.\% & 0.158 & 3.3 & 1.6 & 0.2 & 0.008 & 0.0051 & 0.0047 & 0.034 \\
& mass\% & 0.035 & 1.7 & 0.8 & 0.2 & 0.01 & 0.0029 & 0.0028 & 0.050 \\
\multirow{2}{*}{ L-020 } & at.\% & 0.181 & 3.3 & 1.6 & 0.2 & 0.008 & 0.0038 & 0.0033 & - \\
& mass\% & 0.040 & 1.7 & 0.8 & 0.2 & 0.01 & 0.0022 & 0.0020 & - \\
\hline
\end{tabular}

\subsection{In-situ Study of Selenium Surface Segregation}

For this purpose the cold-rolled sheets were cold-rolled to a final thickness of $0.1 \mathrm{~mm}$. Prior to insertion into the AES spectrometer the specimens were metallographically prepared by grinding and polishing.

For the in-situ study of selenium surface segregation in ultra-high vacuum (UHV) the specimens were resistively heated using alternating current in the chamber of Auger electron spectrometer. ${ }^{13)}$ The surface of the polished specimen was cleaned using Ar-ion sputtering in order to get a clean surface. The temperature was monitored with a $\mathrm{NiCr} /$ $\mathrm{Ni}$ thermocouple which was attached to the specimen. The accuracy of the temperature measurement was $\pm 1^{\circ} \mathrm{C}$.

The temperature was increased from $50^{\circ} \mathrm{C}$ up to $900^{\circ} \mathrm{C}$ in steps of $50^{\circ} \mathrm{C}$ and the specimens were annealed for $5 \mathrm{~min}$ utes at a particular temperature. After each heating step the surface concentration of the elements was determined from the measured AES spectra.

The (HR)AES analyses were also performed during isothermal heating of the specimen. The time period of an isothermal annealing was approximately 50 minutes. Prior to experiment the specimen was cleaned using Ar-ion sputtering.

The spectra were taken using a $10-\mathrm{kV}$ electron-beam energy for the excitation of the Auger electrons and were recorded with a fixed retard ratio 4 of the analyzer. The spectrometer was mounted on an ion-pumped ultra-highvacuum chamber. The typical pressure during the AES analysis was $10^{-7} \mathrm{~Pa}$, which increased to $10^{-5} \mathrm{~Pa}$ during annealing at $900^{\circ} \mathrm{C}$. A Balzers QMS 200 quadrupole mass spectrometer was used to analyze the residual gas during the experiments.

The surface concentrations of the segregands were evaluated from differentiated AES spectra from the peak-topeak ratios (of the segregand in comparison to that of iron) using CasaXPS software. Assuming that the Auger peakheight ratio is proportional to the atomic concentration of the analyzed element the surface concentrations were calculated as follows: ${ }^{14}$

$$
x_{i}^{\text {surf }}=k_{i} \cdot \frac{h_{i}}{h_{F e(703 e V)}}
$$

$x_{i}^{\text {surf }} \ldots$ the surface concentration of the segregand

$k_{i} \ldots$ sensitivity factor related to the segregand and the spectrometer

$h_{i} \ldots$ the peak height of the segregand.

\section{Results}

\subsection{Oxide Scale}

Specimens of $\mathrm{Fe}-\mathrm{Si}-\mathrm{Al}-\mathrm{C}$ alloys were oxidized in a mixture of hydrogen and water vapor at $840^{\circ} \mathrm{C}$ for 15 minutes. The dew point of the gas mixture was $50^{\circ} \mathrm{C}$, which corresponds to $p\left(\mathrm{H}_{2} \mathrm{O}\right) / p\left(\mathrm{H}_{2}\right)$ of 0.12 . After 15 minutes of oxidation at $840^{\circ} \mathrm{C}$ in the wet hydrogen a scale with a subscale of thickness of $4 \mu \mathrm{m}$ grew on selenium doped specimen. The entire scale with a subscale of the selenium-free specimen was non-uniform in thickness (approximately 2-4 $\mu \mathrm{m}$ ), therefore evolving a wavy pattern at the interface with the substrate.

In Figs. 1 and $\mathbf{2}$ the metallographic cross-sections of sele- 
nium-doped and selenium-free specimens of $\mathrm{Fe}-\mathrm{Si}-\mathrm{Al}-\mathrm{C}$ alloy after decarburization annealing are shown.

It is evident that in both cases beneath the external oxide layer internal oxides precipitated. The results of FEG-SEM/
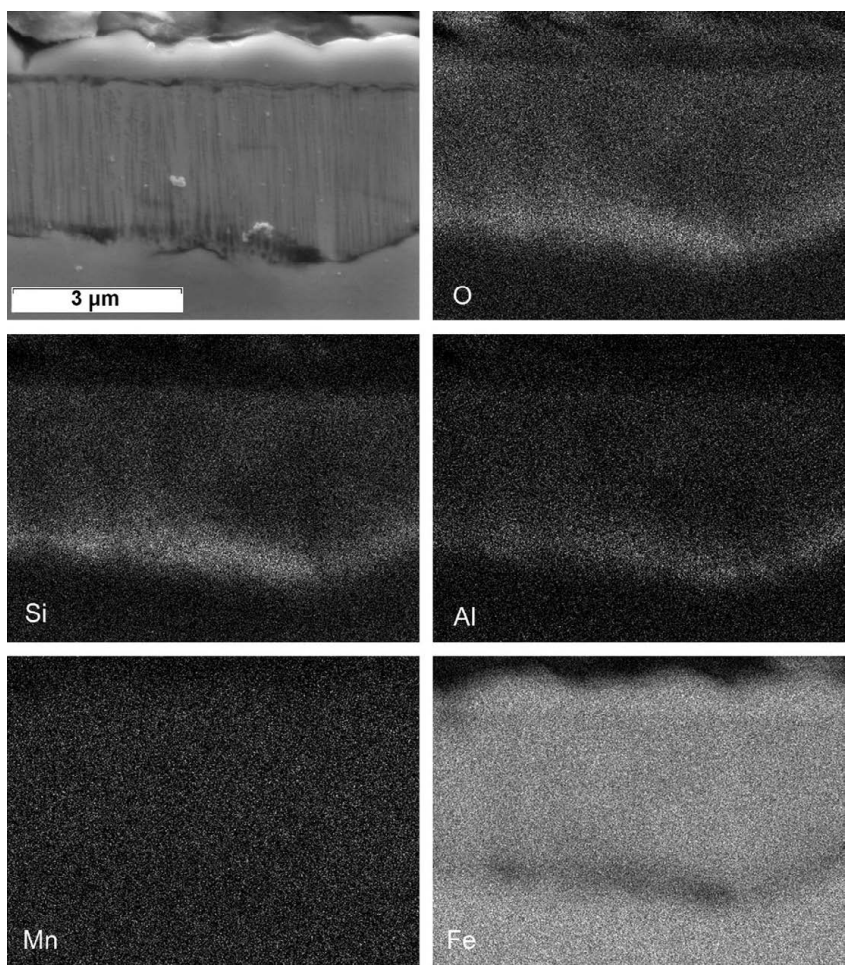

Fig. 1. (a) Cross-section of $\mathrm{Se}$-doped $\mathrm{Fe}-\mathrm{Si}-\mathrm{Al}-\mathrm{C}$ alloy decarburized in $\mathrm{H}_{2} / \mathrm{H}_{2} \mathrm{O}$ at $840^{\circ} \mathrm{C}$ (SE image). Corresponding X-ray mappings show the distributions of $\mathrm{O}, \mathrm{Si}, \mathrm{Al}, \mathrm{Mn}$ and $\mathrm{Fe}$.
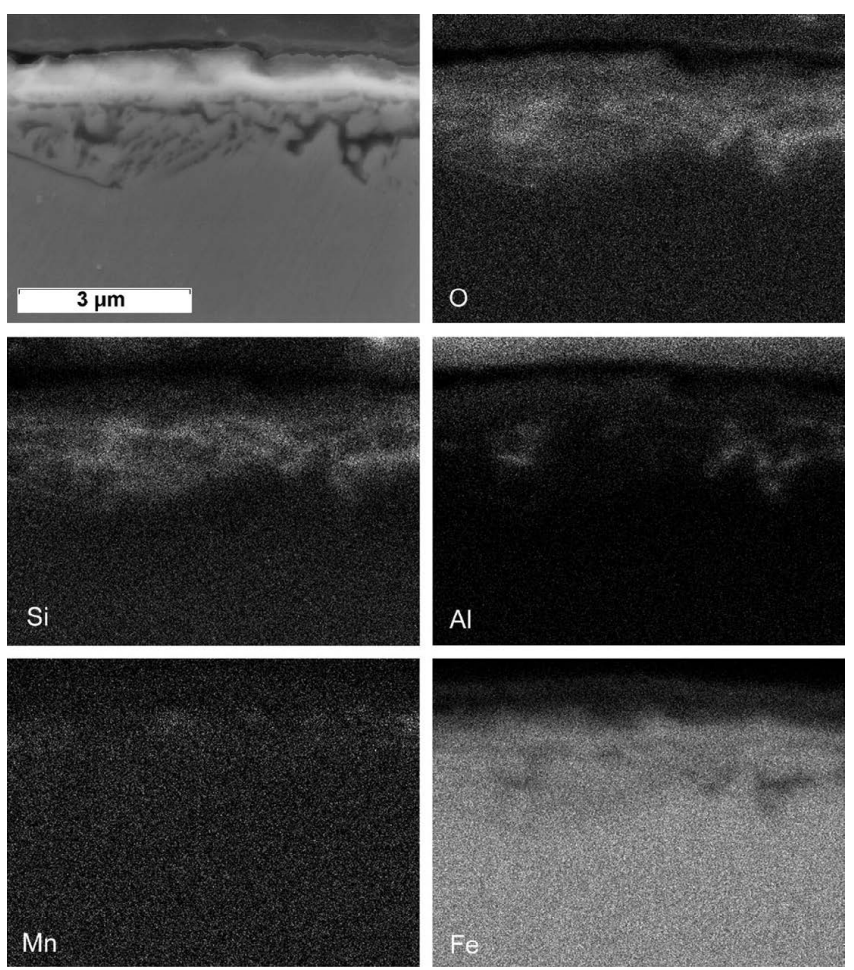

Fig. 2. (a) Cross-section of $\mathrm{Fe}-\mathrm{Si}-\mathrm{Al}-\mathrm{C}$ alloy without selenium decarburized in $\mathrm{H}_{2} / \mathrm{H}_{2} \mathrm{O}$ at $840^{\circ} \mathrm{C}$ (SE image). Corresponding X-ray mappings show the distributions of $\mathrm{O}, \mathrm{Si}, \mathrm{Al}, \mathrm{Mn}$ and $\mathrm{Fe}$.
EDX elemental mapping reveal that the precipitates are enriched in silicon and aluminium.

The morphology of the internal oxides in the seleniumfree specimen is different than that of selenium-doped one. However, the internal oxides of the specimen containing 0.034 at.\% Se demonstrate an obvious columnar preferential growth perpendicular to the steel substrate. In Fig. 1 results of FEG-SEM/EDX analyses further show an Fe-depleted zone and a band of alumina and silica at the interface with the steel substrate.

(HR)AES analyses of the oxidized selenium-doped specimen revealed that the surface of the scale is composed predominantly of iron oxide and silica.

\subsection{Selenium Surface Segregation}

It was assumed that columnar morphology of internal oxides of $\mathrm{Fe}-\mathrm{Si}-\mathrm{Al}-\mathrm{C}$ alloy containing 0.034 at.\% Se could be influenced by selenium surface segregation. Therefore, the selenium surface segregation was investigated.

Figs. 3 and $\mathbf{4}$ show the surface segregation of segregands in $\mathrm{Fe}-\mathrm{Si}-\mathrm{Al}$ alloys during heating in the temperature range of $50-850^{\circ} \mathrm{C}$.

The results of the in-situ AES analysis of the surface segregation of selenium during linear heating of the $\mathrm{Fe}-\mathrm{Si}-\mathrm{Al}$ alloys are given in Table 3. Selenium surface segregation was detectable already at temperatures higher than $350^{\circ} \mathrm{C}$, whereas the onset of more intensive selenium surface-seg-

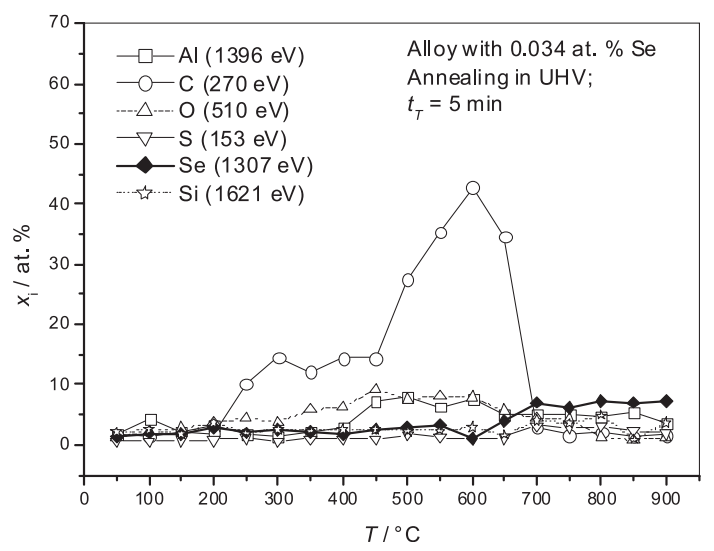

Fig. 3. The surface segregation of elements in a laboratory $\mathrm{Fe}-\mathrm{Si}-$ $\mathrm{Al}$ alloy containing 0.034 at.\% Se.

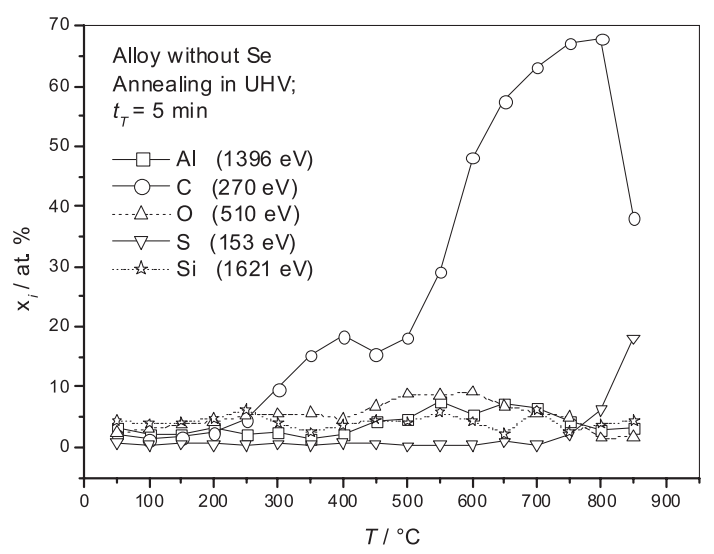

Fig. 4. The surface segregation of elements in a laboratory $\mathrm{Fe}-\mathrm{Si}-$ $\mathrm{Al}$ alloy without Se. 


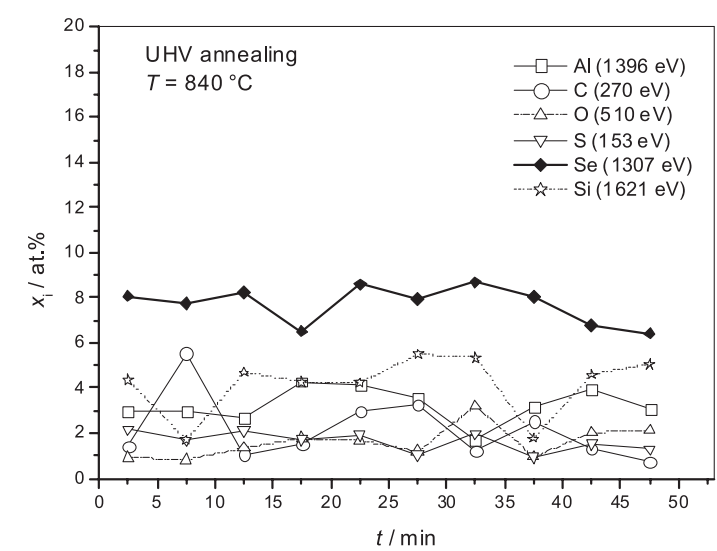

Fig. 5. Selenium surface segregation during annealing of the Sedoped $\mathrm{Fe}-\mathrm{Si}-\mathrm{Al}-\mathrm{C}$ alloy at $840^{\circ} \mathrm{C}$.

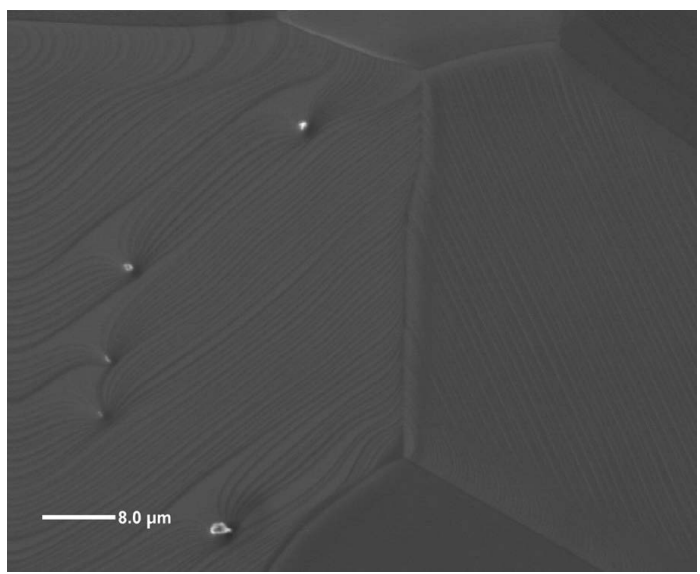

Fig. 6. Facetted crystal grains of the $\mathrm{Fe}-\mathrm{Si}-\mathrm{Al}-\mathrm{C}$ alloy containing 0.034 at.\% Se after annealing in $\mathrm{UHV}$ at $840^{\circ} \mathrm{C}$.

regation was at $650^{\circ} \mathrm{C}$. The surface segregation of selenium reached its maximum value, e.g. 7.3 at.\% at temperature of $T=800^{\circ} \mathrm{C}$.

In addition, the segregation of selenium to the surface of $\mathrm{Fe}-\mathrm{Si}-\mathrm{Al}-\mathrm{C}$ alloy was also investigated during isothermal heating at $840^{\circ} \mathrm{C}$. The evaluation of the results revealed, that selenium surface segregation at $840^{\circ} \mathrm{C}$ is attained already within first measurement, e.g. 2.5 minutes. The time dependence of the intensity of the surface segregation of selenium can be seen from the diagram in Fig. $\mathbf{5}$.

It can be seen in Fig. 5, that the surface coverage of selenium during first 15 minutes of annealing was around 8 at. $\%$. This value decreased to the minimum value of 6 at.\% after approximately 17 minutes. Another peak value of the selenium surface coverage was measured after 22 minutes, when it began to decrease with increasing time of annealing. Due to high temperature of annealing a decrease in the surface coverage can be related to the desorption of selenium from the surface.

After annealing at $840^{\circ} \mathrm{C}$ a reconstructed surface of some ferrite grains was observed. A SE image in Fig. 6 shows a reconstructed surface of pollycrystalline $\mathrm{Fe}-\mathrm{Si}-\mathrm{Al}-\mathrm{C}$ alloy containing 0.034 at. $\%$ Se after annealing in UHV at $840^{\circ} \mathrm{C}$.

\section{Discussion}

The aim of this study was to elucidate the influence of
Table 2. Values of electronegativity, atomic radius, boiling point and heat of vaporization for a variety of segregands, and iron. $^{27)}$

\begin{tabular}{llllll}
\hline & Se & S & Te & Cu & Fe \\
\hline Electronegativity/Pauling Scale & 2.55 & 2.58 & 2.1 & 1.9 & 1.83 \\
Atomic radius cov/pm & 122 & 102 & 147 & 152 & 134 \\
Boiling point $/{ }^{\circ} \mathbf{C}$ & 685 & 444.6 & 988 & 2562 & 2861 \\
Heat of vaporization/kJ/mol & 95.48 & 45 & 114.1 & 300.4 & 340 \\
\hline
\end{tabular}

Table 3. Surface segregation of selenium and carbon in the $\mathrm{Fe}-\mathrm{Si}-$ Al alloys.

\begin{tabular}{lcc}
\hline & L-020 & L-Se19 \\
\hline Selenium content in the bulk material $\left(x_{\mathrm{Se}} / \mathrm{at} . \%\right)$ & - & 0.034 \\
Carbon content in the bulk material $\left(x_{\mathrm{C}} / \mathrm{at} . \%\right)$ & 0.181 & 0.158 \\
Onset of selenium surface-segregation $\left(T /{ }^{\circ} \mathrm{C}\right)$ & - & 650 \\
Onset of carbon surface-segregation $\left(T /{ }^{\circ} \mathrm{C}\right)$ & 250 & 250 \\
Temperature of maximum Se surface conc. $\left(T /{ }^{\circ} \mathrm{C}\right)$ & - & 800 \\
Temperature of maximum C surface conc. $\left(T /{ }^{\circ} \mathrm{C}\right)$ & 800 & 600 \\
Maximum Se surface conc. $\left(x_{\mathrm{Se}} / \mathrm{at} . \%\right)$ & - & 7.3 \\
Maximum C surface conc. $\left(x_{\mathrm{C}} / \mathrm{at} . \%\right)$ & 68.0 & 42.8 \\
\hline
\end{tabular}

selenium on the oxidation behaviour of an $\mathrm{Fe}-\mathrm{Si}-\mathrm{Al}-\mathrm{C}$ alloy, which was decarburized in wet hydrogen at $840^{\circ} \mathrm{C}$.

In decarburization process the carbon from steel reacts with adsorbed oxygen. At the beginning, the limiting factor is the surface reaction between carbon and oxygen. The compound formed is a gas which escapes to atmosphere. The carbon concentration on the surface therefore decreases and an activity gradient of carbon appears consequently. This gradient is the driving force that brings about a diffusion of the carbon atoms from the bulk to towards the surface ${ }^{15)}$ Consequently, the number of carbon atoms available to react with oxygen decreases until becoming the limiting factor of the reaction. Meanwhile on the steel surface, iron and alloying atoms are selectively oxidized and an oxide film starts to grow. When an external scale is formed on the steel surface the effect(s) of the alloying element(s) on the oxidation reactions and mechanisms must also be considered. ${ }^{16-19)}$

In the alloy containing 0.034 at.\% Se a preferential columnar morphology of internal oxides was observed. Here the long penetrating precipitates were observed, perpendicular to the ferrite substrate. The precipitates were enriched in silicon and aluminium. The elements involved in internal oxidation such as silicon and aluminium react with oxygen dissolved on the metal surface and they precipitate. ${ }^{15,20)}$ In addition, a parallel internal-oxide band of silica and alumina at the interface with the steel substrate was clearly evident. Internal-oxide bands form at a finite distance beneath the surface in alloys which have very reactive solutes. ${ }^{21)}$ On the other hand, the scale of selenium-free specimen was slightly thinner and the subscale was non-uniform in thickness. A wavy pattern at the interface with the substrate was observed as is evident in Fig. 2.

The most obvious difference observed in the comparable silicon steel specimens was in the morphology of internal 
oxidation zone.

Selenium is one of the elements in group VI. of the periodic table, chemically related to sulfur and tellurium. In silicon steels it is susceptible to segregation on free surfaces ${ }^{10)}$ and forms (complex) selenide-inclusions. ${ }^{12)}$

Using in-situ (HR)AES analysis selenium surface segregation during annealing at $840^{\circ} \mathrm{C}$ was confirmed. It revealed that selenium surface segregation attained already within first few minutes of annealing and it was not of constant intensity during isothermal annealing. It could be seen from Fig. 5 that the equilibrium surface coverage of selenium could not be established.

The preconditions for the equilibrium surface segregation of nonmetal atoms on metals at higher temperatures are: ${ }^{22)}$

a) the solubility of nonmetal in the metal has to be high enough to prevent depletion of the nonmetal during surface segregation

b) the difusivity of the nonmetal in the bulk of the metal has to be high enough to reach the equilibrium state in acceptable times

c) the loss of segregated nonmetal atoms by desorption has to be negligible.

The solubility of selenium in $\alpha$-Fe and $\gamma$-Fe is very low, ${ }^{23)}$ therefore, its depletion in a subsurface region is possible. Owing to very high vapor pressure of selenium it is suggested that at $840^{\circ} \mathrm{C}$ selenium segregates to the steel surface and also partly evaporates/desorbs from it. The same phenomenon was reported for the copper in $\mathrm{Fe}-\mathrm{Si}-\mathrm{Al}-\mathrm{C}$ alloys. The desorption of copper from the surface started at $500^{\circ} \mathrm{C}$. $^{13)}$

Analogically to these results, ${ }^{13)}$ the process of the surface segregation of selenium during the annealing of $\mathrm{Fe}-\mathrm{Si}-\mathrm{Al}-$ $\mathrm{C}$ alloys could be determined as the dynamic equilibrium:

$$
\mathrm{Se}(\text { dissolved })=\mathrm{Se}(\text { segregated }) \rightarrow \mathrm{Se}(\text { desorbed })
$$

Moreover, after annealing at $840^{\circ} \mathrm{C}$ in ultra high vacuum (UHV) a reconstructed surface of some ferrite grains was observed, as is evident from Fig. 6.

The physical origin of the faceting is well known since 1951. ${ }^{24)}$ Madey and Chen demonstrated ${ }^{25,26)}$ that a variety of electronegative adsorbates with Pauling electronegativities greater than 2.0 will induce faceting at metal surfaces.

In Table 2 electronegativities and some other characteristics for $\mathrm{Se}, \mathrm{S}, \mathrm{Te} \mathrm{Cu}$, and $\mathrm{Fe}$ are given. ${ }^{27)}$

Segregation-induced faceting of the bcc-Fe surfaces was also reported for $\mathrm{Sb}^{28)}$ and $\mathrm{S}^{29)}$ Lin investigated ${ }^{29)}$ the effect of segregated sulfur on the topography of the Fe(111) surface, which is the most open of the low-Miller index $\mathrm{Fe}$ surfaces and possesses the highest surface free energy. The (111) orientation is therefore expected to be morphologically unstable. Facetted (111) surface appears to be a thermodynamic phase since from the thermodynamic perspective the driving force for the faceting is the minimization of the total surface free energy. Sulfur induces reorientation and faceting under formation of low-energy adsorption structures. ${ }^{29,30)}$ The reconstructed (111) surfaces were found to be stabilized by the presence of antimony as well. ${ }^{28)}$

The segregation of the selenium onto the steel surface decreases the surface free energy. The morphology of the internal oxides is determined by the competition between nucleation and growth of precipitates at the reaction front.
The final shape is determined by energy factors. ${ }^{21)}$ It is reported that the adsorption and dissociation of gas molecules can be greatly altered depending on the surface conditions. $^{31)}$

It is proposed therefore, that the difference in the morphology of the internal oxides of Se-doped and Se-free $\mathrm{Fe}-$ $\mathrm{Si}-\mathrm{Al}-\mathrm{C}$ alloy possibly occurred due to a different surface conditions, caused by a selenium surface segregation during the annealing at $840^{\circ} \mathrm{C}$ in a wet hydrogen. At annealing at $840^{\circ} \mathrm{C}$ selenium segregates to the steel surface and also partly evaporates/desorbs from it. The desorption of volatile selenium compounds may also influence the growth of the internal oxidation zone.

Moreover, the comparison of the surface segregation of selenium and carbon in the investigated alloys showed that the intensity of the surface segregation of carbon decreased with an increase in the surface segregation of selenium. This implies that selenium blocked the surface sites for carbon, thus reducing the decarburization ability of Se-containing alloy. About a similar site competition between the carbon and the copper has already been reported. ${ }^{13)}$

\section{Conclusions}

The influence of 0.034 at.\% of selenium on the oxidation behavior of an Fe-Si-Al-C alloy was studied by FEG-SEM/ EDX and (HR)AES.

Selenium doped and selenium free specimens were annealed in a wet hydrogen atmosphere at $840^{\circ} \mathrm{C}$. The morphology of the internal oxides formed on the $\mathrm{Fe}-\mathrm{Si}-\mathrm{Al}-\mathrm{C}$ alloy, which contained selenium exhibited a preferential columnar growth, different from that of undoped alloy.

Using in-situ (HR)AES analysis it was shown that selenium segregates to the steel surface upon annealing at $\mathrm{T}>$ $600^{\circ} \mathrm{C}$. Based on the kinetics of the surface segregation it is assumed that the equilibrium selenium surface-segregation could not be established because of the desorption of segregated selenium from the surface.

It is proposed that the difference in the morphology of the internal oxides of Se-doped and Se-free $\mathrm{Fe}-\mathrm{Si}-\mathrm{Al}-\mathrm{C}$ alloy could possibly occur due to a different surface conditions during the decarburization annealing at $840^{\circ} \mathrm{C}$ due to segregation-induced reconstruction of a steel surface. The desorption of volatile selenium compounds may also influence the growth of the internal oxidation zone.

\section{Acknowledgements}

This article is dedicated to the memory of Professor Hans-Jürgen Grabke ${ }^{\dagger}$ who enabled to begin this study at MPIE, Düsseldorf, Germany. The author also wants to acknowledge Professor Monika Jenko, Head of the Laboratory for the Surface Characterization of Materials, IMT, Ljubljana, Slovenia, where AES measurements were performed. The work was partly supported by Slovenian Research Agency (P. No. P2-0050). The author is very grateful to Mr. Miroslav Pečar, Mr. Bojan Breskvar and Dr. Aleš Nagode for their technical assistance.

\section{REFERENCES}

1) M. F. de Campos, J. C. Teixeira and F. J. G. Landgraf: J. Magn. Magn. Mat., 301 (2006), 94. 
2) K. M. Marra, E. D. A. Alvarenga and V. T. L. Buono: ISIJ Int., 44 (2004), 618.

3) M. F. de Campos, M. Emura and F. J. G. Landgraf: J. Magn. Magn. Mat., 304 (2006), e593.

4) Y. Sidor and F. Kovac: Mater. Design, 26 (2005), 297.

5) H. J. Grabke and G. Tauber: Arch. Eisenhüttenwes., 46 (1975), 215.

6) J. Barros, J. Schneider, K. Verbeken and Y. Houbaert: J. Magn Magn. Mat., 320 (2008), 2490.

7) M. A. da Cunha and S. C. Paolinelli: J. Magn. Magn. Mat., 320 (2008), 2485.

8) D. Steiner Petrovič, M. Godec, B. Markoli and M. Čeh: J. Magn. Magn. Mat., 322 (2010), 3041.

9) M. R. Aboutalebi, M. Isac and R. I. L. Guthrie: Steel Res. Int., 75 (2004), 366.

10) M. Jenko, J. Fine and Dj. Mandrino: Surf. Int. Anal., 30 (2000), 350

11) G. H. Beyer and H. J. Grabke: Steel Res., 70 (1999), 448.

12) D. Steiner Petrovič and M. Jenko: Vacuum, 71 (2003), 33.

13) D. Steiner Petrovič, Dj. Mandrino, S. Krajinovič, M. Jenko, M. Milun, V. Doleček and M. Jeram: ISIJ Int., 46 (2006), 1452.

14) D. Briggs and M. P. Seah: Practical Surface Analysis, Volume 1, Second Edition, John Wiley \& Sons, Chichester, (1994), 201, 335.

15) D. Geneve, D. Rouxel, B. Weber and M. Confente: Mater. Sci. Eng. $A, \mathbf{4 3 5 / 4 3 6}$ (2006), 1

16) H. J. Grabke: Ber. Bunsenges. Phys. Chem., 69 (1965), 409

17) N. Birks, in: Decarburization - The Proc. of the Conf. on Decarburization, The Iron and Steel Institute, London, UK, (1970), 1.
18) J. Kunze: Neue Hütte, 22 (1977), 313.

19) L. Suarez, P. Rodriges-Cavillo, Y. Houbaert and R. Colas: Corros. Sci., 52 (2010), 2044.

20) M. A. A. Motin, J. Zhang, P. R. Munroe and D. J. Young: Corros. Sci., 52 (2010), 3280.

21) D. L. Douglass: Oxid. Met., 44 (1995), 81.

22) H. Viefhaus, H. J. Grabke and Ch. Uebing; in: Landolt-Börnstein: Numerical Data and Functional Relationships in Science and Technology, Group III: Condensed Matter, Vol. 42: Physics of Covered Solid Surfaces, Subvol. A: Adsorbed Layers on Surfaces, Part 3: Surface Segregation and Adsorption on Surfaces, Springer, Heidelberg, (2003), 62.

23) T. B. Massalski: Binary Alloy Phase Diagrams, ASM, Materials Park, Ohio, (1990), 1769.

24) C. Herring: Phys. Rev., 82 (1951), 87.

25) T. E. Madey, J. Guan, C. H. Nien, C. Z. Dong, H. S. Tao and R. A. Campbell: Surf. Rev. Lett., 3 (1996), 1315.

26) S. P. Chen: Surf. Sci., 274 (1992), L619.

27) Handbook of Chemistry and Physics, 90th Edition, CRC Press, Boca Raton, (2009), 1-2804.

28) E. Clauberg, Ch. Uebing and H. J. Grabke: Appl. Surf. Sci., 143 (1999), 206.

29) J. S. Lin, H. Cabibil and J. A. Kelber: Surf. Sci., 395 (1998), 30

30) H. J. Grabke: Materiali in Tehnologije, 40 (2006), 39.

$31)$ S. R. J. Saunders, M. Monteiro and F. Rizzo: Prog. Mater. Sci., 53 (2008), 775. 